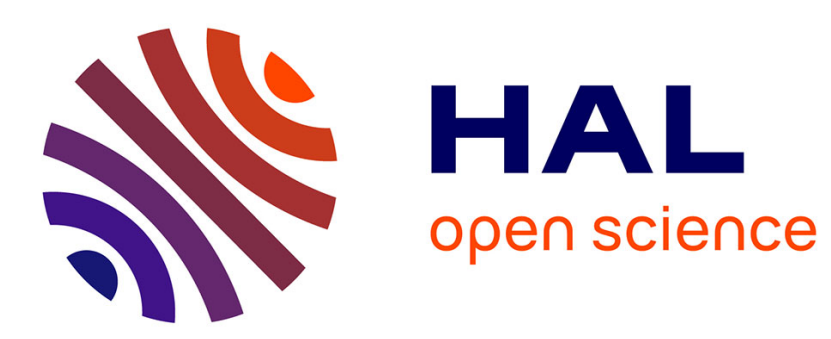

\title{
A 45-GHz wireless transmission for a wireless interconnect network-on-board
}

Thierry Le Gouguec, Pierre-Marie Martin

\section{To cite this version:}

Thierry Le Gouguec, Pierre-Marie Martin. A 45-GHz wireless transmission for a wireless interconnect network-on-board. IEEE worshop on Signal and Power Integriy SPI 2017, May 2017, Baveno, Italy. pp.1 - 2, 10.1109/SaPIW.2017.7944021 . hal-01583298

\section{HAL Id: hal-01583298 \\ https://hal.univ-brest.fr/hal-01583298}

Submitted on 18 Sep 2017

HAL is a multi-disciplinary open access archive for the deposit and dissemination of scientific research documents, whether they are published or not. The documents may come from teaching and research institutions in France or abroad, or from public or private research centers.
L'archive ouverte pluridisciplinaire HAL, est destinée au dépôt et à la diffusion de documents scientifiques de niveau recherche, publiés ou non, émanant des établissements d'enseignement et de recherche français ou étrangers, des laboratoires publics ou privés.

\section{(c)(1)}

Distributed under a Creative Commons Attribution| 4.0 International License 


\title{
A 45-GHz Wireless Transmission for a Wireless Interconnect Network-on-Board
}

\author{
Thierry LE GOUGUEC, Pierre-Marie MARTIN \\ Lab-STICC UMR CNRS 6285, Université de Bretagne Occidentale, Université Bretagne Loire, Brest, France \\ Pierre-Marie.Martin@univ-brest.fr
}

\begin{abstract}
This paper presents the possibilities of radio transmission realizations around the frequency of $45 \mathrm{GHz}$ for wireless communication networks in a "Printed Circuit Board" (PCB) context. First, we present transmission measurement results between two dipole antennas on a multilayer PCB circuit in the 40-50 GHz bandwidth. We also study the effect of metallic obstacles (grid, checkerboard) between our antennas on the same structure. Secondly, from these measurements, we evaluate the expected transmission performances of the propagation channel of our system. In particular, we present the eye diagram simulation results for several configurations and we show that our system is able to achieve data rates of about $2 \mathrm{Gbit} / \mathrm{s}$.
\end{abstract}

Keywords - Wireless Network on Board, Interconnects, Dipole antenna, PCB technology, Transmission, Propagation channel, Eye diagram.

\section{INTRODUCTION}

New electronic applications like HD video for example or new computing servers, are very demanding especially in terms of data rates. One of the factors limiting circuit speed and therefore data rates, comes from conventional metal interconnects on electronic cards. These metal wires occupy a large surface and have the disadvantage of distorting signals (impedance mismatch, electrical crosstalk, ...) because of the increase in working frequencies [1]. Therefore, the risk of transmission error on new electronic circuits is growing. Several alternatives to the classical metal interconnects are envisaged by industrials and in the specialized literature. We note, for example, three-dimensional interconnects, optical links, guided-wave RF interconnects [3] or radio wireless interconnects [4].

Here, we propose to illustrate the wireless transmission possibilities between several circuits placed on an electronic card. The frequency of $45 \mathrm{GHz}$ has been chosen for the carrier signal that allows us to obtain sufficiently small antennas, to be integrated into inter-chip communications in a PCB context. This will also allow us to achieve more data transmission rates.

In the first part, we present an experimental study which permits us to determine the transmission characteristics in different configurations of electronic cards. The results of this study show the optimization possibilities for the transmission level between two antennas placed on a same substrate.
In the second part, we estimate the possible data rates that we can achieve with our "wireless network-on-board", using the afore-mentioned experimental results and additional circuit simulation results.

\section{STUDY OF 45 GHZ RADIO TRANSMISSION ON PCB CARD}

Based on the PCB technology developed during the MIDIMU-HD project, in collaboration with AT\&S company in Austria, we designed multi-layer PCB circuits with dipole antennas placed at the upper metallization level (M1). This technology uses 8 layers of metallization on a MEGTRON 6 dielectric substrate of permittivity $\varepsilon_{\mathrm{R}}=3.6$ and losses tangent $\operatorname{tg}(\delta)=0.006$ up to $45 \mathrm{GHz}$.

In Fig. 1, we present the realized circuits: each of which includes two printed dipole antennas separated by a distance of $10 \mathrm{~mm}$. Three obstacle configurations have been measured: (i) case 1 without any obstacle between two "face-to-face" antennas; (ii) case 2 with a metal grid oriented to the propagation axis and placed between the two antennas at the metallization upper M3 and (iii) case 3 when the grid is replaced by a metal checkerboard.
Case 1
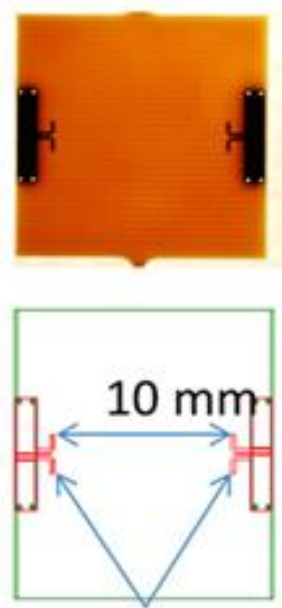

Antenna dipole
Case 2
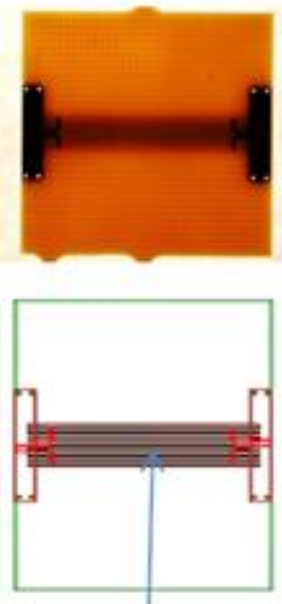

Grid on level 3
Case 3
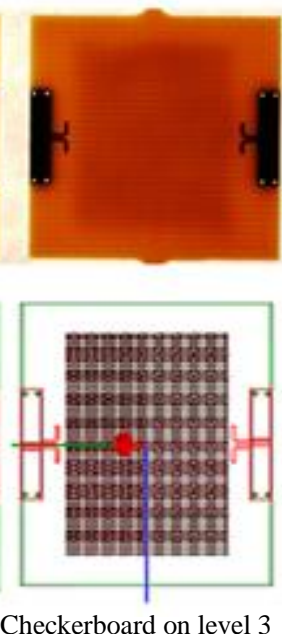

Fig. 1. Examples of realized multilayer circuits on MEGTRON 6 substrate. 
Fig. 2 shows the power transmission gain evolution between an antenna pair. This gain is a function of the $S$ parameters and is defined by the following formula (1):

$$
G_{A}=\frac{\left|S_{21}\right|^{2}}{\left(1-\left|S_{11}\right|^{2}\right)\left(1-\left|S_{22}\right|^{2}\right)}
$$

The $\mathrm{S}_{\mathrm{ij}}$ parameter measurements were performed in the 40$50 \mathrm{GHz}$ bandwidth using a network analyzer. In each case, the measured power transmission gain is between -20 to $-30 \mathrm{~dB}$ on a $4 \mathrm{GHz}$ bandwidth around $47 \mathrm{GHz}$. Here, the gain is very slightly modified by the metallic obstacles. However, we notice a small improvement in this gain in case 2 , with the presence of a grid which is parallel to the radiation axis between the two dipole antennas.

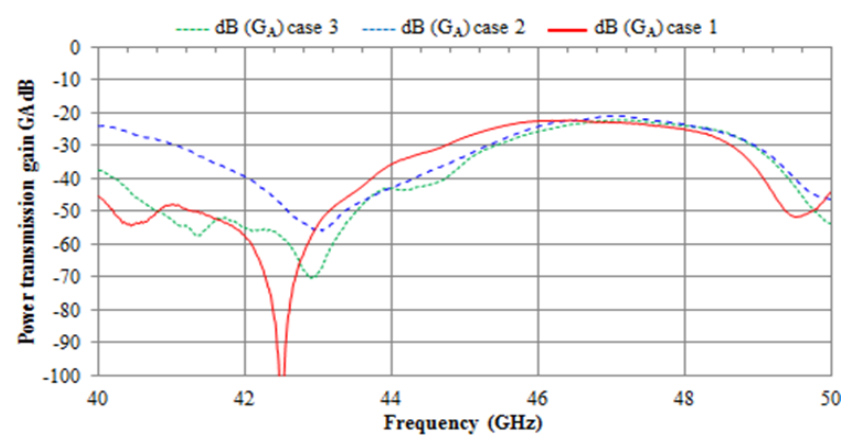

Fig. 2. Power transmission gain $\mathrm{G}_{\mathrm{A}}$ realized between a dipole antenna pair placed on a MEGTRON 6 substrate

\section{ANALYSIS OF EXPECTED DATA RATES}

The measured $\mathrm{S}$ parameters of the previous structures were then used to evaluate the possible digital data rates for this type of transmission.

In Fig. 3, we present the $\mathrm{ADS}^{\mathrm{TM}}$ simulation structure used during this test step.

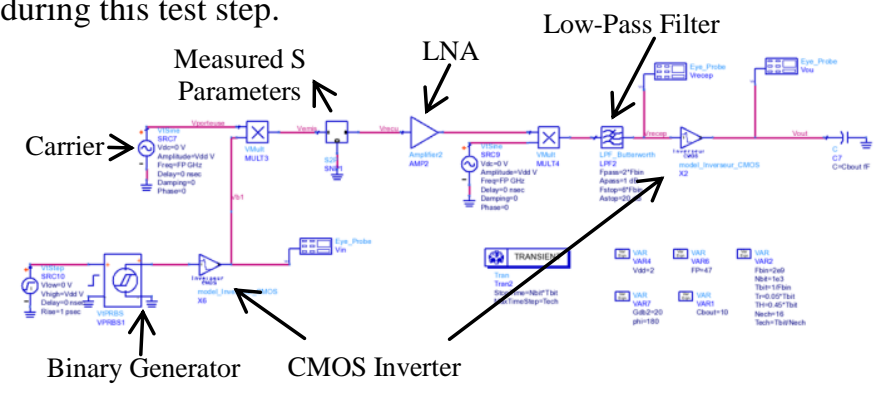

Fig. 3. Simulation scheme for binary information transmission using wireless communication within a PCB card.

We considered here a simple amplitude modulation (OOK type transmitter) based on a carrier frequency at $47 \mathrm{GHz}$. The binary signals have a frequency of $2 \mathrm{GHz}$ and are generated using a logic gate model made using models of $\mathrm{P}$ and $\mathrm{N}$ type CMOS transistors. The receiver is synchronous, it is composed of a $20 \mathrm{~dB}$ gain amplifier, a multiplier and a lowpass filter to eliminate the high frequency signals of the harmonic 2 generated during demodulation. We considered the cutoff frequency of this filter as being twice the frequency of the binary signal. Finally, we use the same model of inverting gate as we did at emission to reshape the signals.

Fig. 4 represents the eye diagrams at reception before and after the inverting gate, for the transmission channel corresponding to the case of two antennas in the presence of a grid at level M3. The characteristics of the eye diagrams before reshaping for the different transmission channels are summarized in Table 1.
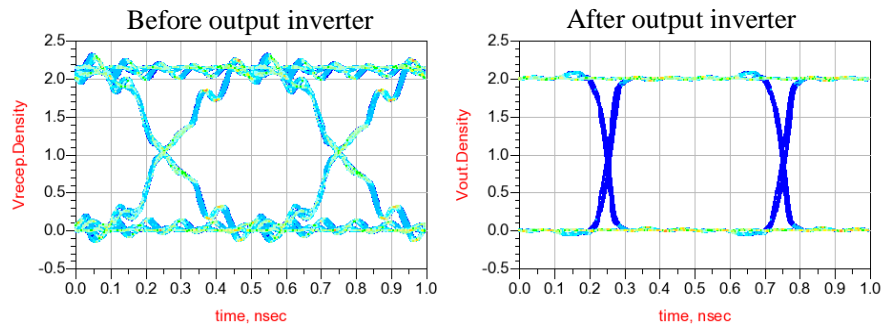

Fig. 4. Transmission eye diagrams between two antennas distant of $10 \mathrm{~mm}$ placed on a MEGTRON 6 substrate

TABLE I. : Eye diagram characteristics

\begin{tabular}{|c|c|c|c|}
\hline Parameter & Case 1 & Case 2 & Case 3 \\
\hline Level “1” $(V)$ & 1,61 & 2,1 & 1,94 \\
\hline Level "0" $(V)$ & $-0,04$ & $-0,02$ & 0,02 \\
\hline Height $(V)$ & 1,37 & 1,96 & 1,59 \\
\hline Width $(V)$ & 0,48 & 0,5 & 0,49 \\
\hline Jitter $(n s)$ & 0,015 & 0,015 & 0,007 \\
\hline Crossing amplitude $(V)$ & 0,78 & 1,03 & 0,91 \\
\hline
\end{tabular}

These last results show the possibilities of transmitting around $2 \mathrm{Gbit} / \mathrm{s}$ of data rates by this type of wireless transmission within multi-layered PCB circuits.

\section{CONCLUSION}

In order to develop wireless networks on PCB cards, we have investigated propagation between two dipole antennas printed on a multilayer substrate. The working frequency chosen here was around $45 \mathrm{GHz}$ in order to reduce antenna dimensions and obtain sufficient digital data rates. We measured a power transmission gain of about $-25 \mathrm{~dB}$, on a 4 $\mathrm{GHz}$ bandwidth between the two antennas.

These results, supplemented by simulations, enabled us to demonstrate the feasibility of transmission of $2 \mathrm{Gbit} / \mathrm{s}$ between two antennas with or without metallic obstacles.

\section{REFERENCES}

[1] Alina Deutsch and al « When are transmission-line effects important for on-chip interconnections ? » IEEE Trans on MTT vol 45, n 10 October 1997.

[2] ITRS 2015.

[3] Y.C. Mombo Boussougou and al «Electromagnetic analysis of RF interconnect » IEEE SPI 2008 Avignon.

[4] P.M Martin and al «Wireless interconects by using printed antennas for inter-chip communications in PCB context » EuMC 44th 2014 Rome, pp 1789-1792. 